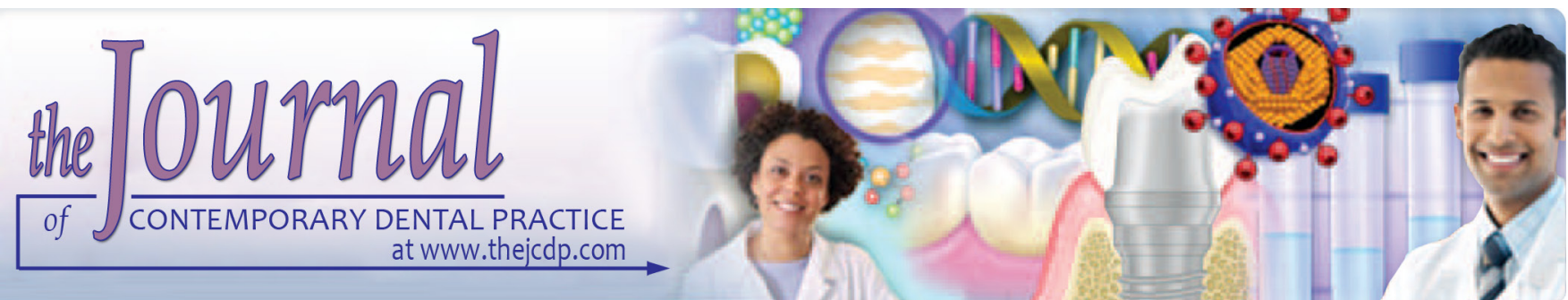

\title{
Evaluation of Shear Bond Strength of Three Different Acrylic Resin and Artificial Denture Teeth with and without Monomer Application
}

\author{
${ }^{1}$ Navleen Dandiwal, ${ }^{2}$ Sandeep Kumar, ${ }^{3}$ Shashikala Jain, ${ }^{4}$ Rajnish Aggarwal, ${ }^{5}$ Nancy Singla, ${ }^{6}$ Nandalur K Reddy
}

\section{ABSTRACT}

Aim: To compare and evaluate the shear bond strength of the tooth-denture base junction when three different commercially available acrylic resin base bonded to acrylic teeth with and without application of methyl methacrylate monomer on ridge lap area.

Materials and methods: A three-stepped cylindrical shaped die was customized. Sixty samples were fabricated with heat cure and self-cure acrylic resin with and without monomer application. A total of 60 samples were divided into three groups and six subgroups.

- Group A-Twenty samples of Trevlon-HI heat-activated acrylic resin.

- Subgroup $A_{1}$-Ten samples of acrylic teeth bonded with Trevlon-HI heat- activated acrylic resin with the application of monomer on ridge lap area.

- Subgroup $A_{2}$-Ten samples of acrylic teeth bonded with Trevlon-HI heat-activated acrylic resin without application of monomer on ridge lap area.

- Group B-Twenty samples of Trevalon heat-activated acrylic resin.

- Subgroup $B_{1}$-Ten samples of acrylic teeth bonded with Trevlon heat-activated acrylic resin with the application of monomer on ridge lap area.

- Subgroup $B_{2}$-Ten samples of acrylic teeth bonded with Trevlon heat-activated acrylic resin without application of monomer on ridge lap area.

- Group C-Twenty samples of Trevlon-RR self-activated acrylic resin.

- Subgroup $C_{1}$-Ten samples of acrylic teeth bonded with Trevlon-RR self-activated acrylic resin with the application of monomer on ridge lap area.

\footnotetext{
${ }^{1-5}$ Department of Prosthodontics, Surendera Dental College \& Research Institute Sriganganagar, Rajasthan, India

${ }^{6}$ Department of Prosthodontics, College of Dentistry, Jazan University, Jazan, Kingdom of Saudi Arabia

Corresponding Author: Navleen Dandiwal, Department of Prosthodontics, Surendera Dental College and Research Institute, Sriganganagar, Rajasthan, India, Mobile: 9521497105, e-mail: navleend16.nd@gmail.com
}

- Subgroup $C_{2}$-Ten samples of acrylic teeth bonded with Trevlon-RR self-activated acrylic resin without monomer application on ridge lap area.

Results: Samples obtained from high impact heat cure acrylic resin with monomer application shows higher bond strength when tested under the universal testing machine.

Conclusion: With and without monomer application on high impact polymethylmethacrylate (PMMA) resin and Heat cured resin it was found that high impact shows better bond strength. Trevlon $\mathrm{HI}$ monomer shows a greater increase in strength due to the presence of cross-linking agents.

Clinical significance: The incorporation of mechanical surface treatments followed by monomer application significantly influences the bonding between denture teeth and denture base resin.

Keywords: Artificial teeth high impact acrylic resin, Debonding, Surface properties, Surface treatment.

How to cite this article: Dandiwal N, Kumar S, Jain S, Aggarwal R, Singla N, Reddy NK. Evaluation of Shear Bond Strength of Three Different Acrylic Resin and Artificial Denture Teeth with and without Monomer Application. J Contemp Dent Pract 2019;20(1):94-100.

Source of support: Nil

Conflict of interest: None

\section{INTRODUCTION}

Denture base materials are a group of related substances. The chemical name for the resin produced from the MMA is PMMA. MMA is a transparent and colorless fluid substance. A characteristic feature of PMMA is its high transparency. The reason for this continued popularity is the simple processing equipment required and the relatively low cost of the fabrication process. Acrylic resins were introduced in the 1940s and have been serving dentistry till today. ${ }^{1}$ Previously materials such as vulcanite, nitrocellulose, phenol, formaldehyde, vinyl plastic, and porcelain were used for denture base construction. $^{2}$ 
Acrylic resin teeth are most widely used as artificial teeth. Included among the many advantages, acrylic teeth make stronger overall one-unit denture because of a better bond between teeth and denture base resin. ${ }^{3}$ To overcome the disadvantage of fracture acrylic resin teeth are modified by using cross-linking agents, different monomers and the addition of fillers. New types of artificial teeth using a modified acrylic resin that incorporates cross-linking agents and a composite resin containing filler have been reported to demonstrate lower bond strength to denture base resin when compared to conventional acrylic resin teeth. Therefore the ridge lap portion of the teeth is expected to be the least cross-linked as to facilitate bonding to the denture base resin. ${ }^{4}$

Chemical or mechanical modification of ridge lap portion of the denture tooth has been done to improve the strength of denture teeth to an acrylic resin denture base. Ridge lap grinding, bonding agent, cross-linking agent concentration solvents or monomer-polymer solution application, presence of separating medium, surface grooving, tooth material, denture base material, impurities or wax contamination, thermo cyclic microwave polymerization temperature rise these are the factors investigated to improve strength between the denture base and acrylic resin. ${ }^{1}$

Polymethylmethacrylate (PMMA) has been used for denture teeth and base fabrication. Acrylic resin teeth bond chemically to denture base which is necessary to prevent de-bonding, increase stiffness and strength. Dentures made today are fabricated from heat cured polymethyl methacrylate and reinforced polymethyl methacrylate. High impact strength acrylics employ a PMMA polymer modified by adding a rubber compound to improve strength properties. Over the years, curing procedures have been modified intending to enhance the physical and mechanical properties of resin materials. Different polymerization methods have used: heat, light, chemical and microwave energy. Conventional PMMA material can be used for this technique. Therefore it is prudent to evaluate and compare the bond strength of self-activated polymerizing acrylic resin, heat activated polymerizing acrylic resin, and high-impact heat activated polymerizing acrylic resin with the toothdenture base. ${ }^{4}$

\section{MATERIALS AND METHODS}

Total of 60 samples was prepared from a custom made die which was further divided into three groups and six subgroups.

- Group A-Twenty samples of Trevlon-HI heat-activated acrylic resin.
- Subgroup $A_{1}$-Ten samples of acrylic teeth bonded with Trevlon-HI heat- activated acrylic resin with the application of monomer on ridge lap area.

- Subgroup $A_{2}$-Ten samples of acrylic teeth bonded with Trevlon-HI heat- activated acrylic resin without application of monomer on ridge lap area.

- Group B-20 samples of Trevlon heat-activated acrylic resin

- Subgroup $B_{1}-$ Ten samples of acrylic teeth bonded with Trevlon heat-activated acrylic resin with the application of monomer on ridge lap area.

- Subgroup $B_{2}$-Ten samples of acrylic teeth bonded with Trevlon heat-activated acrylic resin without application of monomer on ridge lap area.

- Group C-20 samples of Trevlon-RR self-activated acrylic resin

- Subgroup $C_{1}$-Ten samples of acrylic teeth bonded with Trevlon-RR self-activated acrylic resin with the application of monomer on ridge lap area.

- Subgroup $C_{2}$-Ten samples of acrylic teeth bonded with Trevlon-RR self-activated acrylic resin without monomer application on ridge lap area.

\section{Description of the Custom made Tooth Embedding Die}

Jar-shaped die with $30 \mathrm{~mm}$ diameter was customized having a central opening in which $5 \mathrm{~mm}$ diameter disc with $3 \mathrm{~mm}$ diameter rod can be pushed up and reseated back as shown in Figure 1.

\section{Description of the Custom made Die with Coverlid}

A three-stepped cylindrical shaped die was customized. The upper cylinder was $5 \mathrm{~mm}$ in diameter, and $2.5 \mathrm{~mm}$ in height and the middle cylinder was $30 \mathrm{~mm}$ in diameter. The base cylinder was of $50 \mathrm{~mm}$ diameter upon which cover lid fits. The cover lid has $30 \mathrm{~mm}$ internal diameter



Fig. 1: Stepped cylindrical die 
and four escape channels of $4 \mathrm{~mm}$ width in the wall of the lid. When the cover lid was placed upon the stepped cylindrical die upper cylinder contacts the cover lid at the center (Fig. 2).

Each denture tooth was embedded in auto polymerizing methacrylate PMMA using metal embedding die. Central disc in the die was lifted by pushing up the rod. Ridge lap surface of the tooth was attached upon the central disc with cyanoacrylate. Rod was pulled, and the disc was reseated back. Thus, the tooth was positioned in the center of die base. End of the disc was flushed with the surface of the base to ensure proper seating. The self-cure acrylic resin was mixed according to the manufacturer's instructions and then poured in the die. Cellophane paper along with glass slab was pressed lightly to remove excess self-cure resin material. After polymerization of the self-cure resin, the central rod was pushed up slowly, and methacrylate PMMA cylinder with the embedded tooth was taken out. The obtained self-cure cylinder was of the same dimension as of disc (30 mm) diameter (Fig. 3).

\section{METHODS OF DATA COLLECTION}

\section{Standardization of Specimen}

Each denture tooth was embedded in auto polymerizing acrylic resin using a special embedding stainless steel mold made of $30 \mathrm{~mm}$ (diameter) x $30 \mathrm{~mm}$ (height) and $5 \mathrm{~mm}$ diameter hole at center with $3 \mathrm{~mm}$ diameter stop hole inside it. In this hole, a lift rod assembly was placed having central $5 \mathrm{~mm}$ diameter disc with lift rod $(3 \mathrm{~mm}$ diameter x $20 \mathrm{~mm}$ length). Upon the disc, ridge lap surface of the tooth was attached with cyanoacrylate glue so that tooth was positioned exactly in the center with $5 \mathrm{~mm}$ of ridge lap surface for the treatment. Lift rod was pushed after polymerization of embedding material to obtain a sample of similar dimension as of the mold.
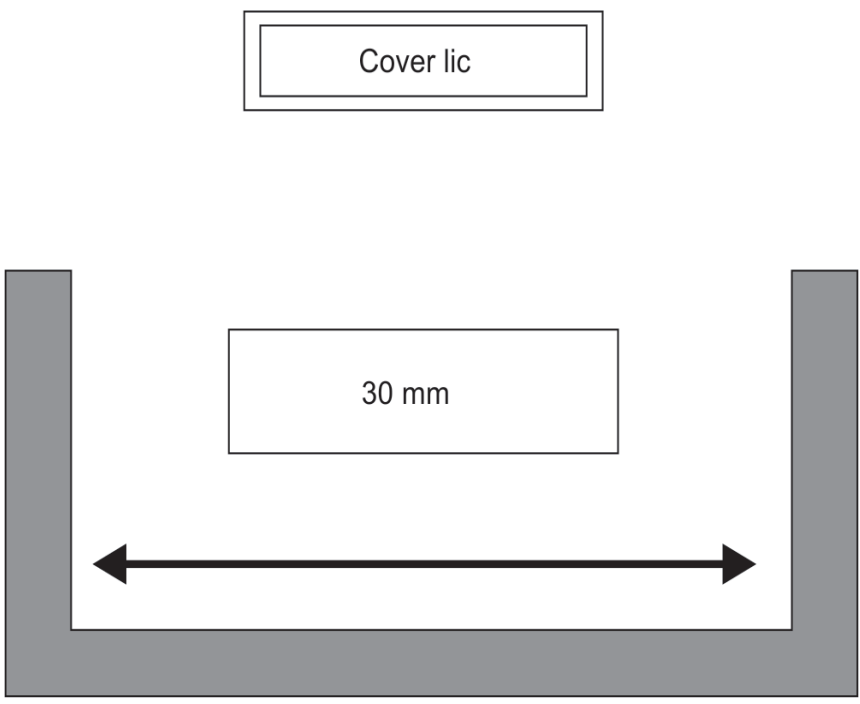

Fig. 2: Cover lid

\section{Preparation of Tooth Surface}

The entire test specimens were surface treated with a 120 silicon carbide grit paper on the ridge lap surface.

\section{Preparation of Wax Model}

Stainless steel mold was prepared to obtain silicone patterns of the same diameter as of embedded auto polymerizing acrylic resin (30 $\mathrm{mm}$ diameter) with a circular projection (5.0 $\mathrm{mm}$ diameter $\times 2.5 \mathrm{~mm}$ length) to standardize the dimensions of the denture base resin cylinder. Cyanoacrylate glue was applied to the silicone pattern PMMA/polymer interface, so the silicone pattern opening position coincides with the prepared ridge-lap surface. Then, the circular opening of the silicone pattern was poured with sticky wax.

\section{Preparation of Molds}

The prepared models were invested in the flask using dental stone. A mechanical vibrator was used to prevent air trapping during investing. One hour later when the final set of dental stone was achieved; flasks were kept for de-waxing by immersing in the de-waxing unit for 5 minutes. Wax was thoroughly removed using boiling water and detergent (Fig. 4).

\section{Processing of Specimens with Compression Molding Technique}

A mixture of polymer and monomer in the ratio given by manufacturer was proportioned before mixing. Mixing was carried out in a porcelain jar, and once the mix reached the dough consistency, it was kneaded by hand to increase its homogeneity and then packed in the mold. The test specimens for subgroup A were pre-wetted with methyl methacrylate monomer on ridge lap area for 30 seconds before packing. Flasks were then closed with the cellophane sheet in between

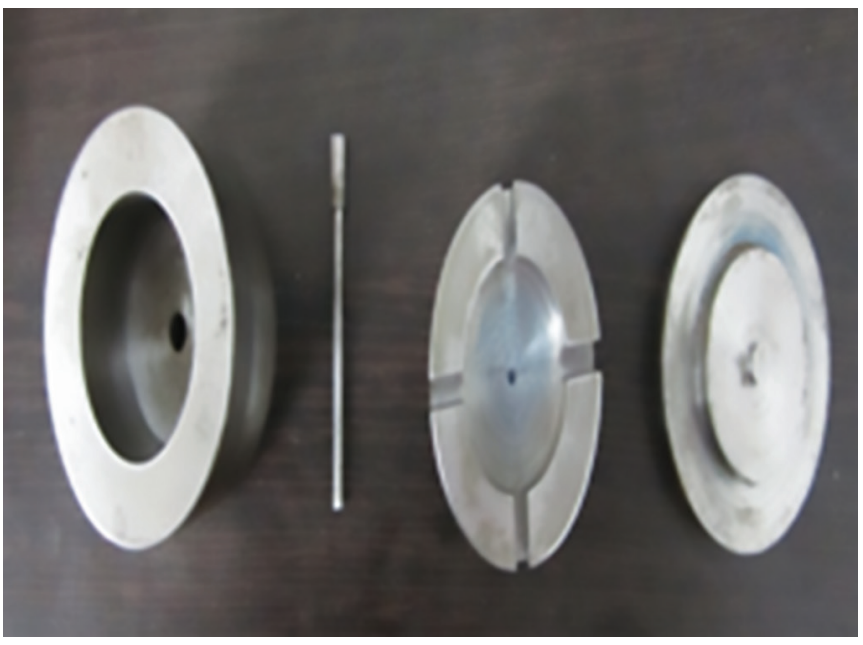

Fig. 3: Stainless steel die 


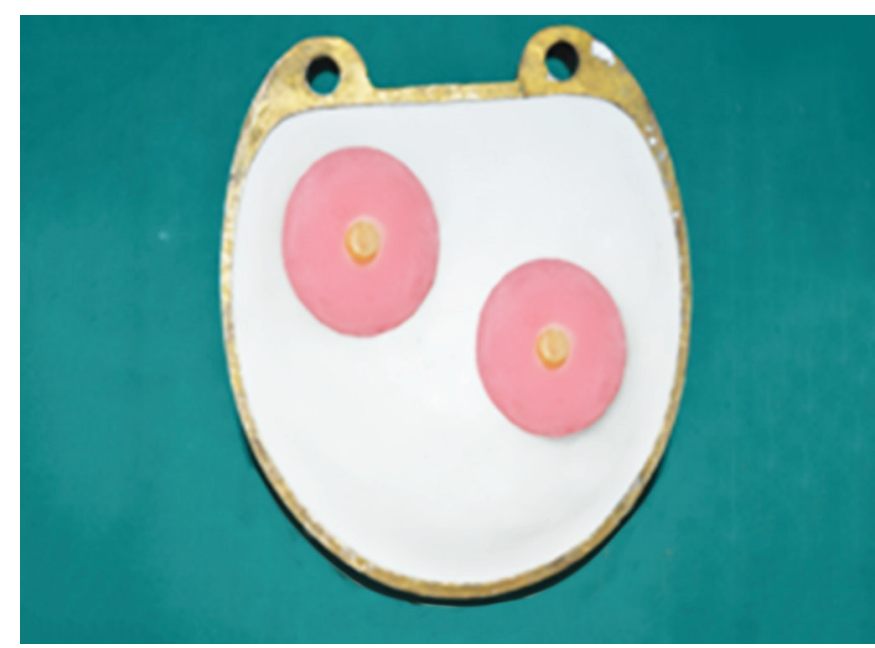

Fig 4: Samples invested

them. Trial closure was carried out using a hydraulic press. Excess of material was trimmed using a BP blade (no. 22). Finally, the flasks were clamped, and final closure was done under pressure of $20 \mathrm{KN}$ and kept for 30 minutes. Then the flasks were immersed in water in an acrylizer at room temperature and processing was done according to the manufacturer's recommendation.

After curing and bench cooling to room temperature the specimen were deflasked and excess denture base material is removed. Specimens were visually inspected before they are used. Those with voids or cracks were discarded.

\section{Failure Load Test}

Failure load was carried out on the universal testing machine. Each specimen was placed in a jig and held secure to avoid any change of position. A shear load was applied to the denture base resin cylinder at $130^{\circ}$ using the universal testing machine at a crosshead speed of 1 $\mathrm{mm} / \mathrm{minute}$ until failure occurs.

After the testing of the samples, the reading obtained were recorded and statistically analyzed (Fig. 5).

Table 1: Mean and SD values of bond strength reading in $A 1$, A2, B1, B2, C1, C2 under study.

\begin{tabular}{|c|c|c|c|c|}
\hline Variables & $\begin{array}{l}\text { Mean } \pm S . D \\
\text { (Shear bond } \\
\text { strength) }\end{array}$ & $\begin{array}{l}\text { Confidence } \\
\text { interval }\end{array}$ & T-test & $p$ value \\
\hline $\begin{array}{l}\text { Heat cure with } \\
\text { Monomer (A1) }\end{array}$ & $11.68 \pm 3.51$ & \multirow{2}{*}{$-2.75-3.35$} & \multirow{2}{*}{0.21} & \multirow{2}{*}{0.84} \\
\hline $\begin{array}{l}\text { Heat cure without } \\
\text { Monomer(A2) }\end{array}$ & $9.66 \pm 2.95$ & & & \\
\hline HI with Monomer (B1) & $12.68 \pm 3.44$ & \multirow[b]{2}{*}{$-0.44-5.24$} & \multirow[b]{2}{*}{1.77} & \multirow[b]{2}{*}{0.09} \\
\hline $\begin{array}{l}\text { HI without Monomer } \\
\text { (B2) }\end{array}$ & $10.28 \pm 2.54$ & & & \\
\hline $\begin{array}{l}\text { RR with Monomer } \\
\text { (C1) }\end{array}$ & $9.96 \pm 3.52$ & \multirow{2}{*}{$-0.81-5.71$} & \multirow{2}{*}{1.58} & \multirow{2}{*}{0.13} \\
\hline $\begin{array}{l}\text { RR without Monomer } \\
\text { (C2) }\end{array}$ & $9.23 \pm 3.44$ & & & \\
\hline
\end{tabular}

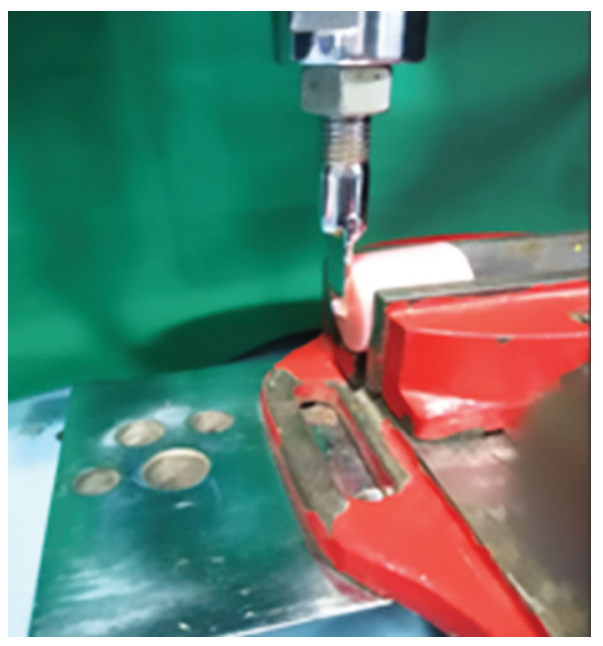

Fig 5: Sample testing

\section{OBSERVATIONS AND RESULTS}

The present study was conducted to evaluate the effect of surface treatments on the bond strength of selfpolymerizing acrylic resin, heat polymerizing acrylic resin, high-impact heat polymerizing acrylic resin with the tooth-denture base. After testing the samples, the data obtained were tabulated and subjected to statistical analysis using ANOVA test and the student's' test ( $p$ value $<0.05$ )

Table 1 and Graph 1 shows the distribution of mean and $S D$ values of bond strength reading in $A_{1}, A_{2}, B_{1}, B_{2}$, $\mathrm{C}_{1}, \mathrm{C}_{2}$ under study. It can be noted that the mean readings of bond strength of heat cure with monomer $\left(\mathrm{A}_{1}\right)$ is 11.68 mean $(S D=3.51)$, heat cure without monomer $\left(A_{2}\right)$ is 9.66 mean, $(\mathrm{SD}=2.95)$, high impact heat cure with monomer (B) is 12.68 mean, (SD = 3.44), high impact heat cure without monomer $(\mathrm{B} 1)$ is 10.28 mean, $(\mathrm{SD}=2.54)$, Rapid repair with monomer $\left(C_{1}\right)$ is 9.96 mean, $(S D=3.52)$, Raid repair without monomer $\left(C_{2}\right)$ is 9.23 mean, $(S D=3.44)$ although the values obtained are insignificant group $\mathrm{A}_{1}$, $\mathrm{B}_{1}, \mathrm{C}_{1}$ shows higher shear bond strength.

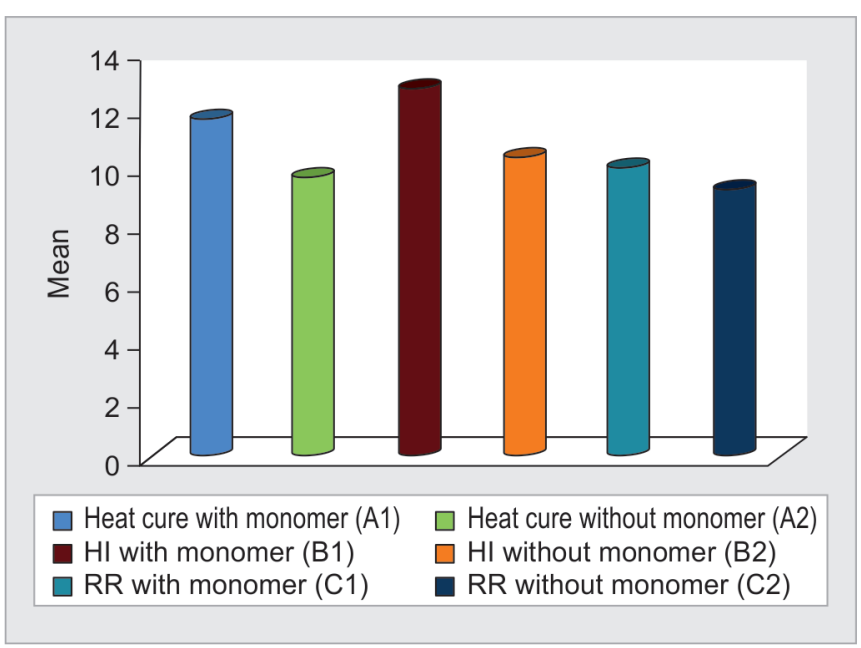

Graph 1: Mean and SD values of bond strength reading in $A 1$, A2, B1, B2, C1, C2 under study. 
application on the ridge lap area. The greater amount of cross-linking agent in the monomer is the reason for such increased bond strength. The use of a solution containing a solvent and polymerizable monomer has been advocated for bonding of plastics. This is required to bond cold curing resin to acrylic resin teeth with a bond strength that is similar to those obtained when heat curing resins are used. This solvent-polymerizable (Monomer) swelling the surface and permits diffusion of the material. On polymerization, a network of polymer chains is interwoven that results in tensile strength of up to $80 \%$ that of the parent plastic. The strength of the bond is dependent on the degree of penetration of the solvent and the strength of the interwoven polymer chains. ${ }^{6}$

Solvent action of dichloromethane increases due to the presence of polymerizable monomer. Swelling of the solvent polymerizable system occurs and this permits diffusion of polymerizable material. According to Rupp, ${ }^{6}$ Chung, ${ }^{7}$ Takahashi ${ }^{8}$ dichloromethane enhances diffusion of methyl methacrylate and also acts as a nonpolymerizable solvent. The value of bond strength increased after modification with surface abrasion of ridge lap. This happens due to the production of numerous fine capillaries which permit mechanical interlocking. These findings are in agreement with studies done by Civjan Fletcher, ${ }^{9}$ Casewell, and Norling, ${ }^{10}$ Chung. ${ }^{7}$

Slightly higher strength bond values achieved when tooth base roughening with abrasive rotary instruments than those achieved without surface modification. ${ }^{11}$ The physical properties such as chemical bonding and wear resistance between artificial teeth and denture base are of prime importance for acrylic resin teeth. Highly cross-linked denture teeth have good abrasion resistance it was found with growing research work. But as every coin has two sides; one major drawback is poor adhesive bonding with highly cross-linked teeth to the denture base. Therefore to facilitate bonding the ridge lap portion of the teeth is expected to be the least cross-linked to the denture base resin. ${ }^{4}$

A force was applied at a 130-degree angle of the tooth. Zukerman ${ }^{12}$ used to stress their test specimens similar forces were applied. To simulate functional forces this angle was chosen. The tensile loads used in many artificial tooth bond strength studies are not representative of real conditions either. The direction of occlusal forces and the expulsive anatomic shape of anterior teeth make the occurrence of significant tensile forces over these teeth unlikely. On the other hand, compressive and shear load and are much more plausible clinically, especially considering the angulated load applied by the authors. A bond test was carried out in a Computerized
Universal Testing Machine, (Pune, India) with 400 $\mathrm{N}$ load cell at a crosshead speed of $1 \mathrm{~mm} / \mathrm{min}$. The compressive load was accomplished with a steel knife edge near the bond surface margin until fracture occurred. ${ }^{13}$

In this study as compared to conventional heat cure poly-methyl-methacrylate resin the high impact denture base resin showed a better bond strength to acrylic teeth with and without monomer application because of a monomer containing a greater amount of crosslinking agent (ethylene glycol di-methacrylate), i.e., TREVALON HI monomer is having highest bond strength. This study is supported by authors like Morrow, ${ }^{14}$ Cardash, $^{15}$ Cunningham. ${ }^{16}$ From the data gathered from tables, it is evident that the maximum values for bond strength were obtained with application of HI monomerDichloromethane combination in 1:1 ratio applied 3 to 4 minutes before dough packing (Chung, Rupp, Takahashi). ${ }^{17-19}$

\section{CLINICAL SIGNIFICANCE}

The incorporation of mechanical surface treatments followed by monomer application significantly influences the bonding between denture teeth and denture base resin. High impact heat activated, heat activated, self-activated

denture base materials with acrylic tooth with ridge lap area grounded half of its length was used, and it was found that high impact heat-activated denture base materials show higher bond strength compared to the other groups, further application of monomer on the ridge lap area in high impact heat activated, heat activated, selfactivated shows higher bond strength compared to the other denture base resins without the use of monomer application.

\section{CONCLUSION}

In this present study, test specimens were divided into three groups and each group is having two subgroups. A load was applied at the tooth and denture base resin interface at $130^{\circ}$ to its long axis using the universal testing machine at a crosshead speed of $1 \mathrm{~mm} / \mathrm{min}$ until failure load occurs. High impact heat activated, heat activated, self-activated denture base materials with acrylic tooth with ridge lap area grounded half of its length was used and it was found that high impact heat-activated denture base materials shows higher bond strength compared to the other groups, further application of monomer on the ridge lap area in high impact heat activated, heat activated, self-activated shows higher bond strength compared to the other denture base resins without the use of monomer application. 


\section{REFERENCES}

1. Madhav GV, Raj S, Yadav N, Mudgal I, Mehta N, Tatwadiya R. Shear bond strength of acrylic teeth to acrylic denture base after different surface conditioning methods. J Contemp Dent Pract. 2013 Sep 1;14(5):892-897.

2. Cunningham JL: Shear bond strength of resin teeth to heatcured and light-cured denture base resin. J Oral Rehabil 2000;27:312-16.

3. Barpal D, Curtis DA, Finzen F, Perry J, Gansky SA. Failure load of acrylic resin denture teeth bonded to high impact acrylic resins. The Journal of prosthetic dentistry. $1998 \mathrm{Dec}$ 1;80(6):666-671.

4. Amit v Nayak: Complete denture fractures: A clinical study. The Journal of Indian Prosthodontic Society 2009;9(3): 148-50.

5. Yadav NS, Somkuwar S, Mishra SK, Hazari P, Chitumalla R, Pandey SK. Evaluation of bond strength of acrylic teeth to denture base using different polymerization techniques: A comparative study. Journal of international oral health: $\mathrm{JIOH}$. 2015;7(Suppl1):54-56.

6. Rupp NW, Bowen RL, Paffen Barger GC. Bonding cold curing denture base acrylic resin to acrylic resin teeth. J Am Dent Assoc 1971;83(3):601-06.

7. Chung RW, Clark RK, Darvell BW. The bonding of cold cured acrylic resin to acrylic denture teeth. Australian dental journal. 1995 Aug;40(4):241-245.

8. Takahashi Y, Chai J, Takahashi T, Habu T. Bond strength of denture teeth to denture base resins. International journal of prosthodontics. 2000 Jan 1;13(1)59-65.

9. Fletcher AM. A method of improving the bonding between artificial teeth and PMMA. Journal of Dentistry 1985;13(2):102-108
10. Caswell CW, Norling BK. Comparative study of the bond strength of three abrasion resistant plastic denture teeth bonded to a cross linked and a grafted, cross linked denture base material. J Prosthet Dent 1986;55:701-708.

11. Bragaglia EL, Prates LHM and Calvo MCM: The role of surface treatments on the bond between acrylic denture base and teeth. Braz Dent J 2009;20:41-5.

12. Zuckerman GR. A reliable method for securing anterior denture teeth in denture bases. The Journal of prosthetic dentistry. 2003 Jun 1;89(6):603-607. 13. M o r e V and Dange SP: Comparative evaluation of chemical and mechanical modifications of ridge lap area on bond strength between denture base resin and teeth. J Ind Prostho Society 2004;4:29-32.

14. Morrow RM, Matvias FM, Windeler AS, Fuchs RJ. Bonding of plastic teeth to two heat curing denture base resins. J Prosthet Dent 1978;38:565-568.

15. Cardash HS, Liberman R, Helft M. The effect of retention grooves in acrylic resin teeth on tooth denture base bond. J Prosthet Dent 1986;55:526-528.

16. Cunningham JL and Benington IC: An investigation of the variables which may affect the bond between plastic teeth and denture base resin. I Dent 1999;27:129-35.

17. Chung KH, Chung CY, Chung CY, Chan DC. Effect of pre processing surface treatments of acrylic teeth on bonding to the denture base. Journal of oral rehabilitation. 2008 Apr;35(4):268-275.

18. Rupp NW, Dickson G, Lawson ME, Sweenew WT. A method for measuring the mucosal surface countour of impression, cast and dentures. J Am Dent Assoc 1957;54:24-32.

19. Takahashi Y, Chai J. Assessment of shear bond stength between three denture reline materials and a denture base acrylic resin. Int J Prothodont 2001;14(6):531-535. 